\title{
Arvind Bhave (ed): Emerging techniques in spine surgery
}

\author{
Jaypee Brothers Medical Publishers Ltd, New Delhi, 2009, 286 pp, CD ROM, Hard- \\ cover, 100,00 US\$, ISBN: 978-81-8448-696-4
}

\author{
Daniel Gastambide
}

Received: 20 December 2010/ Accepted: 21 December 2010/Published online: 20 February 2011

(C) Springer-Verlag 2011

This is the first book to offer a complete overview of all the endoscopic techniques, namely endoscopic spine surgery with 4- to 6-mm-diameter working tubes, vertebroplasty, interspinous implants, nucleus arthroplasty and laminoplasty.

A special chapter focuses on spinal tumour surgery while Anthony Yeung describes foraminal endoscopic surgery in detail, and we learn more about interlaminar discectomy, a new approach improved by Gun Choi. A targetted fragmentectomy technique is recommended for extra-foraminal disc herniations.

Ho-Yeon Lee and Sang-Ho Lee write about percutaneous endoscopic thoracic discectomy and percutaneous endoscopic cervical discectomy. Sri Kantha and Brinda Kantha explain cervical and lumbar facet joint denervation by radiofrequency and laser. These two authors have added another chapter about thoracic and lumbar sympathectomy using the same method as previously described. Arvind Bhave provides clear illustrations of vertebroplasty.

Single balloon kyphoplasty using a far lateral extrapedicular approach is described by Chun-Kun Park's team while Darwono A. Bambang provides an outline of vesselplasty. It consists of a kind of vertebral stent, which seems very efficient, fairly straightforward to use, and very affordable.

A chapter by Rick C. Sasso and James E. Lashley is dedicated to arthroplasty, and more particularly cervical disc arthroplasty with many details about the different kinds of prosthesis.

Harsh Priyadarshi and Ashish Diwan cover the TDR with a biomechanical approach.

With authorization of copyright by ArgoSpine News and Journal: doi:10.1007/s12240-010-0007-1.

D. Gastambide $(\square)$

Centre Tourville, Paris, France

e-mail: danielgastambide@free.fr
Another section deals with total posterior arthroplasty. It shows how this system provides an alternative to fusion in mono-segmental stenosis.

Charles Dean Ray and Orson James May, having been working for the past 20 years on nucleus arthroplasty devices, provide a list of twelve kinds of systems; whereas the world of interspinous implants is covered by Marek Szpalski and Robert Gunzburg and exemplified by four types of implants.

Ho-Yeon Lee and Sang-Ho Lee deal with interspinous locker fixation using artificial ligaments. Alexander R. Vaccaro discusses pedicular screw-based dynamic stabilization with different systems $\left(\right.$ Graf $^{\circledR}$, Dynesys $\left.^{\circledR}\right)$ and describes eight other options.

Sang-Ho Lee, Jun-Ho Lee, and Ho-Yeon Lee describe multi-level oblique corpectomy without fusion. Tataru Shiraishi gives an outline of selective laminoplasty including skip laminectomy. The chapter about videoassisted thoracoscopic fusion is well documented by HeeKit Wong and Gabriel K. P. Liu.

Cervical pedicle screw fixation is explained by $\mathrm{Ku}-$ niyoshi Abumi. Furthermore, Christian Mazel describes tumorectomies by using a minimal invasive approach. In the final sections, Jin-Fu Lin and Myun-San Moon explain symptomatic "vacuum phenomenon" of lumbar discs, and S. Rajasekaran addresses the association of tuberculosis with kyphosis.

This book is a very precise summary of the multiple techniques, which are developing all around the world, and it should allow fostering exchange between surgeons to improve their techniques and the patients' treatment outcomes. This book is therefore a must-have for all spine surgeons.

Conflict of interest No funds were received in support of this study. 